\title{
A seismic monitoring approach to detect and quantify river sediment mobilisation by steelhead redd-building activity
}

Michael Dietze, GFZ German Research Centre for Geosciences, Section 4.6 Geomorphology, Potsdam, Germany (mdietze@gfz-potsdam.de),

James Losee, Washington Department of Fish and Wildlife, Olympia, Washington, USA (James.Losee@dfw.wa.gov).

Lina E. Polvi, Department of Ecology and Environmental Science, Umeå University, Umeå, Sweden (lina.polvi@umu.se).

Daniel Palm, Department of Wildife, Fish and Environmental Studies, Swedish University of Agricultural Sciences, Umeå, Sweden (Daniel.Palm@slu.se)

\begin{abstract}
The role of spawning salmonids in altering river bed morphology and sediment transport is significant yet poorly understood. This is due, in large part, to limitations in monitoring the reddbuilding process in a continuous and spatially extended way. A complimentary approach may be provided through the use of a small seismic sensor network analyzing the ground motion signals generated by the agitation of sediment during the redd building process. We successfully tested the viability of this approach by detecting and locating artificially-generated redd signals in a reach of the Mashel River, Washington State, USA. We then utilize records of 17 seismic stations, in which we automatically detected seismic events that were subsequently manually checked, yielding a catalogue of 45 potential redd-building events. Such redd-building events typically lasted between one and twenty minutes and were comprised of a series of clusters of 50-100 short energetic pulses in the $20-60 \mathrm{~Hz}$ frequency range. The majority (> $90 \%$ ) of these redd building events occurred within eleven days, predominantly during the early morning and late afternoon. The seismically derived locations of the signals were in agreement with independently mapped redds. Improved network geometry and installation conditions are required for more efficient detection, robust location and improved energetic insights to redd building processes in larger reaches. The passive and continuous nature of the seismic approach in detecting redds and describing fish behavior provides a novel tool for fish biologists and fisheries managers, but also for fluvial geomorphologists, interested in quantifying the amount of sediment mobilised by this ecosystem engineer. When complemented with classic approaches, it could allow for a more holistic picture of the kinetics and temporal patterns (at scales from seconds to multiple seasons) of a key phase of salmonid life cycles, with potential implications for biology, ecology, and fluvial geomorphology.
\end{abstract}

This paper is the second, revised version of a peer reviewed preprint uploaded to EarthArXiv, and submitted to "Earth Surface Processes and Landforms".

Potsdam, 12 June 2020 


\title{
A seismic monitoring approach to detect and quantify river sediment mobilisation by steelhead redd-building activity
}

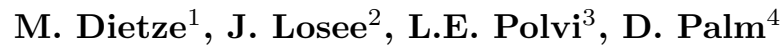 \\ ${ }^{1}$ GFZ German Research Center for Geosciences, Section 4.6 Geomorphology, Potsdam, Germany, Tel.: \\ +4933128828827 \\ ${ }^{2}$ Washington Department of Fish and Wildlife, 600 Capitol Way N. Olympia, Washington, USA, 98501 \\ ${ }_{3}^{3}$ Department of Ecology and Environmental Science, Umeå University, 90187 Umeå, Sweden \\ ${ }^{4}$ Department of Wildlife, Fish and Environmental Studies, Swedish University of Agricultural Sciences, \\ 90183 Umeå, Sweden
}

\section{Key Points:}

- Environmental Seismology

- Ecosystem Engineers

- Salmonid Spawning

- Gravel-bed Rivers

- Biogeomorphology

Corresponding author: Michael Dietze, mdietze@gfz-potsdam.de 


\section{Abstract}

The role of spawning salmonids in altering river bed morphology and sediment transport is significant yet poorly understood. This is due, in large part, to limitations in monitoring the redd-building process in a continuous and spatially extended way. A complementary approach may be provided through the use of a small seismic sensor network analysing the ground motion signals generated by the agitation of sediment during the redd-building process. We successfully tested the viability of this approach by detecting and locating artificially-generated redd signals in a reach of the Mashel River, Washington State, USA. We then utilize records of 17 seismic stations, in which we automatically detected seismic events that were subsequently manually checked, yielding a catalogue of 45 potential redd-building events. Such redd-building events typically lasted between one and twenty minutes and were comprised of a series of clusters of 50-100 short energetic pulses in the $20-60 \mathrm{~Hz}$ frequency range. The majority $(>90 \%)$ of these reddbuilding events occurred within eleven days, predominantly during the early morning and late afternoon. The seismically derived locations of the signals were in agreement with independently mapped redds. Improved network geometry and installation conditions are required for more efficient detection, robust location and improved energetic insights to redd-building processes in larger reaches. The passive and continuous nature of the seismic approach in detecting redds and describing fish behaviour provides a novel tool for fish biologists and fisheries managers, but also for fluvial geomorphologists, interested in quantifying the amount of sediment mobilised by this ecosystem engineer. When complemented with classic approaches, it could allow for a more holistic picture of the kinetics and temporal patterns (at scales from seconds to multiple seasons) of a key phase of salmonid life cycles.

\section{Introduction}

In the form of ecosystem engineers or bioturbators, biota can have significant effects on physical earth surface processes (Viles, 1988). Examples include biological weathering (de Oliveira Frascá \& Del Lama, 2018), slope stabilization by vegetation (Phillips et al., 2016) and river bank destabilization by invading species (Harvey et al., 2019). Within rivers, ecosystem engineers and bioturbators serve both to trap sediment and reduce erosion, such as beaver and riparian plants stabilizing stream banks, and to increase erosion and sediment transport, such as grazing animals and crayfish (Polvi \& Sarneel, 2018). While many of these examples are easily detectable and can be surveyed continuously, some biotically-driven causes of sedimentation or erosion are much harder to constrain using traditional methods, and only their resulting effects can be surveyed. For example, nest building in riverine systems by salmonids is a process that affects river bed sediment movement (Gottesfeld et al., 2004; Hassan et al., 2008) but is rarely monitored in real time.

Salmonid spawning includes building a nest, known as a redd, where eggs are placed and incubated until emergence. The process of redd construction includes the rapid movements of the caudal fin by the female, which agitates the bed material and ultimately transports sediment from a site to excavate a pit. The entire redd-building process has been shown to take up to five days (Burner, 1951) but detailed information on this process is limited. After the initial pit has been excavated, the female deposits eggs in the pit where they are fertilized by one or more males (Quinn, 2018). The eggs are then buried by the female through additional excavation upstream of the pit. Depending on the species, the spawning event and associated redd construction involves the excavation of a significant amount of gravel- and cobble-sized sediment. Specifically, the total length of a redd ranges from $0.31 \mathrm{~m}$ to greater than $3 \mathrm{~m}$ depending on stream dynamics, species and size of the female (Burner, 1951; Losee et al., 2016). For example, S. Gallagher and Gallagher 
(2005) documented redds for the anadromous form of Oncorhynchus mykiss also known as steelhead, averaging $0.72 \mathrm{~m}$ in length.

The process of redd building by salmonids has been associated with the removal of benthic organisms (Field-Dodgson, 1987) and sediment transport consistent with that observed during flood events (Gottesfeld et al., 2004). For example, Hassan et al. (2008) found in a selection of small North American streams that in years with low-recurrence interval snow melt floods, redd building by salmonids transported as much sediment as fluvial processes. In years of high flows and dynamic flooding events, salmonids may not directly transport as much sediment as natural fluvial processes but serve to enhance sediment mobility by reducing armouring (Hassan et al., 2008). As scarce as such empirical evidence currently may be, they illustrate that an important consequence of reddbuilding can be an altered river bed morphology, by increasing the diversity in river bed morphology, generating a deposit protruding from the riverbed, decreasing armouring and decreasing the degree of particle imbrication (e.g. Rennie \& Millar, 2000; Hassan et al., 2008). Over geological time scales, this may alter longitudinal profiles of rivers and increase the erosion efficiency of the entire catchment (Fremier et al., 2018). On the contrary, a biologically induced increase of bed roughness may also result in reduced shear stress. In summary, the medium- to long-term effect of salmonid-induced river bed reorganization is uncertain given the limited number of quantitative studies on this topic, leading only to idealized formulation approaches in long-term models (e.g. Fremier et al., 2018).

Likewise, detailed information on the timing and duration of redd-building activity is unknown. Traditionally, biologists and fisheries managers have relied on the visual identification and enumeration of salmonid redds to determine spawning stock biomass and spawn timing. This work is done through regular monitoring activities, involving one or more stream surveyors visually identifying, enumerating and marking spawning sites every seven to ten days (S. P. Gallagher et al., 2007; Madel \& Losee, 2016). Apart from constraining the creation within the lapse time of surveys, retrospective mapping (e.g. Losee et al., 2016) has been used to provide detailed information on the morphology and geometric properties of the redd but provides limited information regarding the timing of redd construction, duration of spawning events and other behavioural characteristics. More detailed information associated with redd-building activity has emerged through selected snorkel surveys (e.g. Rand \& Fukushima, 2014), and laboratory studies (Needham \& Taft, 1934; Berejikian et al., 2008). These approaches have the advantage of delivering direct high resolution information on the fish's activity during spawning but are limited to daylight or very simplified conditions. Together, none of the existing approaches have been shown to provide a continuous, high resolution and spatially extended record of redd-building activity in a given reach of a river.

An alternative and potentially complementary approach to detect, describe and enumerate spawning sites may be provided by environmental seismology, an emerging research field that investigates the seismic signals emitted by Earth surface processes. Modern seismic sensors like geophones or broadband seismometers are sensitive enough to detect processes that emit only minimal impact energy to the ground, such as falling rain drops and wind turbulence (Turowski et al., 2016; Dietze et al., 2017), or rock and ice crack signals (Polvi et al., in review). Seismic sensors have already been used to study sediment mobilization in rivers (Burtin et al., 2016; Schmandt et al., 2017), a process which is inherently difficult to constrain under natural conditions due to the infrequent occurrence of transport, often under hostile flow conditions. There, sediment particles impacting the river bed emitted seismic signals with a characteristic spectral signature, and these signals could be inverted for the mass of sediment that is moving through the river's cross section at a given time interval (e.g. Dietze, Lagarde, et al., 2019).

In this study, we us a small seismic network in an important steelhead (Oncorhynchus mykiss) spawning area, the Mashel River, Washington State, USA, to investigate whether 
the redd-building process of steelhead can be detected and located using seismic signals. We also aim to describe fine-scale temporal and spatial patterns of redd construction from observed seismic signals.

\section{Study site and instrumentation}

The Mashel River is a tributary of the Nisqually River, which originates from the Nisqually Glacier on the slopes of Mt. Rainier and drains $1,890 \mathrm{~km}^{2}$ of the western slope of the Cascade Mountain Range. Our study reach was approximately $150 \mathrm{~m}$ long on a $2^{\text {nd }}$ order stream segment of the Mashel River. Bankfull width ranged from approximately 25-70 $\mathrm{m}$ and average bed slope was $0.0005 \mathrm{~m} / \mathrm{m}$. The sediment size distribution was fairly well sorted, composed of coarse gravel to cobbles, with a $\mathrm{D}_{16}$ of $19.4 \mathrm{~mm}, \mathrm{D}_{50}$ of 55.1 $\mathrm{mm}$, and $\mathrm{D}_{84}$ of $123.1 \mathrm{~mm}$. This reach was chosen based on the high density of steelhead spawners in past years relative to other parts of the Mashel River. To relate seismic signals to environmental conditions, we used daily meteorological data (NOAA, 2020) and 15-min discharge data (USGS, 2020).

We deployed 17 seismic stations on land on the left and right banks, approximately 2-5 meters from the bank, except for four stations (Fig. 1 a) that were placed at greater distance to explore the spatial range of river-derived signals. Stations were installed with an average spacing of $25 \mathrm{~m}$ (average river width) as an irregular network. Since we did not know the ideal network design for the type of signals we recorded, we chose this setup based on pragmatic decisions. The installed stations consisted of PE6B 4.5 Hz vertical component geophones and Digos DataCube data loggers recording at $400 \mathrm{~Hz}$. The spikeequipped sensors were pushed into the ground and the loggers were placed next to the sensor. For longer term installations, one would either place the sensors in pits or cover them with sediment to shield them from atmospheric signals. However, due to the amount of sensors and time constraints this was not possible in this study. The system was equipped with internal batteries, allowing for up to 2 weeks of continuous operation and maintained with fresh batteries for the life of the study (approximately 4 weeks). The stations were deployed on 29 April 2019 and dismantled on 27 May 2019. To constrain essential seismic ground properties, we performed an active seismic survey. For this, a metal plate $(25 \times 10 \mathrm{~cm})$ was placed directly next to individual seismic stations and signals were induced by ten subsequent blows with a $5 \mathrm{~kg}$ sledge hammer.

The potential spectral properties of the redd-building process were inspected by manually mimicking redd-building activities, using three different approaches, for approximately one minute each: 1) In the first approach, a person created a hydraulic jet that entrained sediment by intensively flipping a rubber diving fin with its hands. 2) The bed material was moved around at the same site with a boot. 3) Finally, the bed material was gently agitated with a stiff paddle, again without touching the sediment. Before and after each experiment, we exerted a sequence of three hits with a hammer onto a boulder at the left bank of the river to identify each experiment's start and end time.

The study area was visited at regular intervals and manually surveyed for new redd features (26 April, 08 May, 13 May, and 23 May 2020). The same two trained surveyors were responsible for identifying redds for the duration of the study. Surveyors wore polarized glasses and recorded locations of steelhead redds using standardized survey methodology (Madel \& Losee, 2016). As mentioned above, redds that are constructed by salmonids typically include a well-defined depression (pit) immediately upstream of a mound (tail spill). These features are also identifiable as being absent of macrophytes. Each redd was flagged with the date, the surveyor's initials, and other descriptive details as needed to avoid double-counting redds. Additionally, coordinates of redd locations were recorded using a hand-held GPS. We assumed that all observed redds were created by steelhead; this was based on several factors: 1) the absence of other salmonids during the sampling period; 2) the observed presence of adult steelhead; and 3) the relatively large size of ob- 
a)
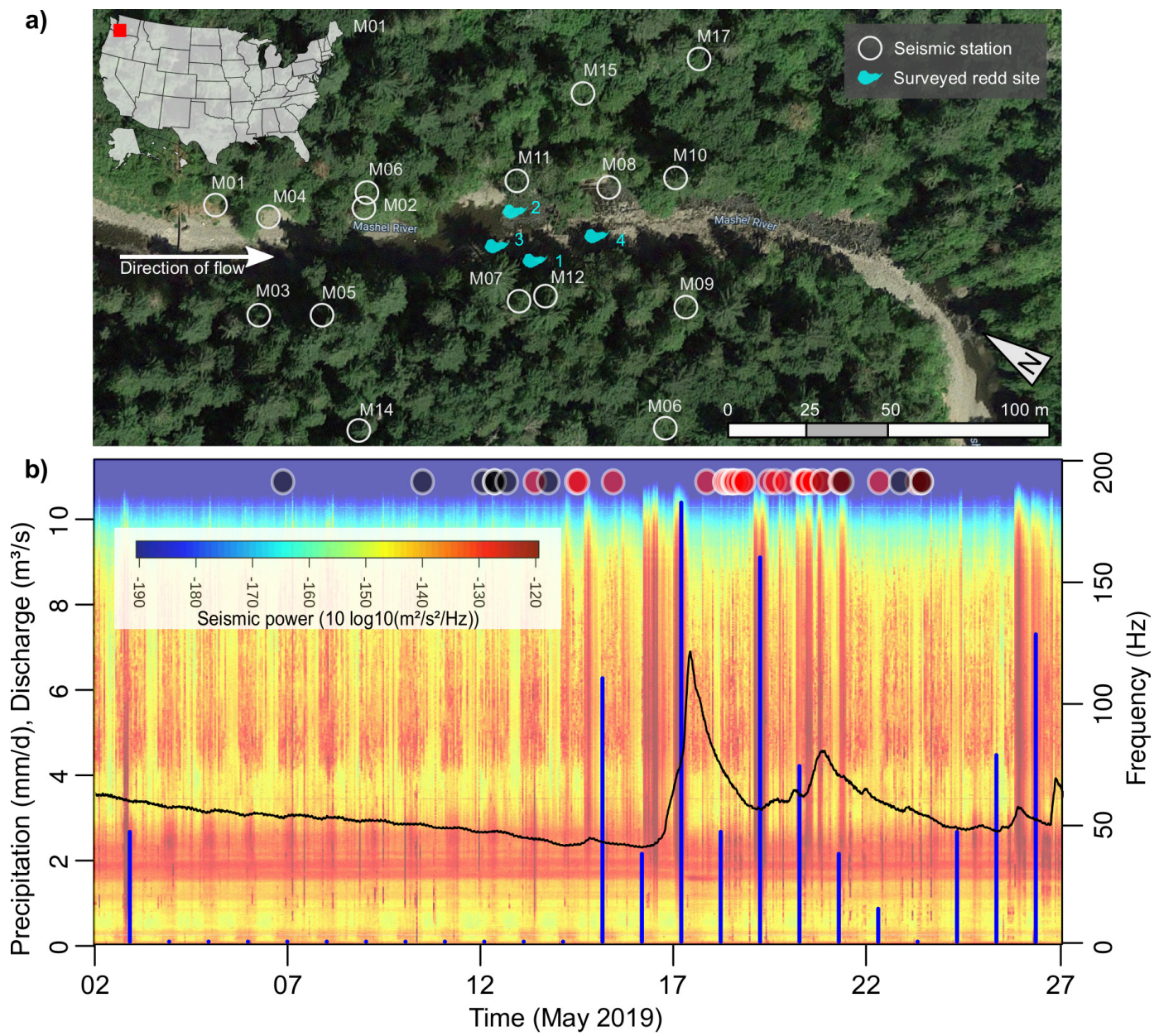

Figure 1. Study area with instrumentation scheme and environmental data. a) The $150 \mathrm{~m}$ long straight reach of the Mashel River, Washington State, USA, was instrumented by 17 seismic stations. Redd sites (blue polygons) found during periodic mapping campaigns are located inside the seismic network. Aerial image source: Google Maps. b) Precipitation (blue bars, NOAA station Mayfield Power Plant) and discharge data (black line, station USGS no. 12087000) for the instrumented period. Circles at the top depict manually identified seismic events; black circles are regular events, red circles are events only recorded at station M11, cf. Tab. 1 for details. Background shows a seismic spectrogram of the full period as recorded by station M11.

served redds relative to those of other redd-building species potentially present (cutthroat trout Oncorhynchus clarkia clarkii and Pacific Lamprey Entosphenus tridentatus).

\section{Data processing}

All seismic data were processed with the $R$ package eseis v 0.6.0 (Dietze, 2018a, 2018b). The SI contain dedicated R scripts of all major processing and analysis steps. Seismic data were also interactively visualised using the software Snuffler v. 2018.1.29 (Heimann et al., 2017). Raw measurement files were converted from the Cube logger data format to hourly files (SAC format, IRIS, 2017), organised in a coherent structure (see SI). 
To identify discrete events from the continuous stream of ground motion data, we applied a classic STA-LTA trigger algorithm (Allen, 1982), which is sensitive to sudden rises in ground motion amplitudes. We applied this algorithm to hourly signal snippets of all analysed stations, overlapping by 5 minutes on both sides. Hourly snippets (400 times 3600 samples) turned out to be ideal in terms of computer memory balance, and the overlap guaranteed that we did not miss events at the snippet margins. The signals were detrended, filtered between 10-20 Hz (window showing the least spectral overlap with the river as constant seismic source) and envelopes, representing hull functions of the signals, were calculated (see SI for code and details). For the subsequent STA-LTA algorithm, we used a short time window of $0.5 \mathrm{~s}$, a long time window of $180 \mathrm{~s}$, an on-ratio of 5 and an off-ratio of 1 . The window sizes were based on the assumption that potential events would show a rapid and impulsive onset and would not last longer than three minutes. Since the algorithm usually detects many spurious events, we removed all picks with durations less than $0.2 \mathrm{~s}$ and longer than 5 min to ensure that signals were not spurious and represented gravel transport results from fish movement. Events shorter than $0.2 \mathrm{~s}$ are usually spurious instantaneous spikes (Dietze et al., 2017), whereas events longer than a few minutes are caused by earthquakes or anthropogenic sources such as trains or, especially in this particular study, planes (see results). Furthermore, we removed events that were not recorded by at least three stations and within a joint occurrence time window of $1 \mathrm{~s}$, because signals must be detected by at least three stations in order to locate the signal source. The seismic wave velocity in loose sediment is typically a few hundred $\mathrm{m} / \mathrm{s}$ (Bourbie et al., 1987); therefore, for a maximum distance of $167 \mathrm{~m}$ across the utilised network, a seismic wave from a source to a station requires less than $1 \mathrm{~s}$.

In order to identify potential redd-building events, all remaining events were checked manually for consistency and validity. Checks were based on the following criteria: 1) presence of short pulses, forming clusters of activity that lasted less than one minute (Needham \& Taft, 1934), 2) absence of systematically increasing and decreasing amplitudes, indicative of approaching and passing terrestrial animals, including humans, 3) absence of distinct arrivals of seismic phases, indicative of earthquakes; and 4) absence of gliding frequency bands (e.g. Fig. 3 a), typical for planes. These criteria were investigated both by studying the raw seismic waveforms interactively and by computing spectrograms, plots of the time evolution of seismic power spectra. The spectrograms were computed using the sub/window averaging technique (Welch, 1967) of deconvolved signals (see SI).

The manually-validated events were located using the signal migration technique (Dietze, 2018b). This approach makes use of the finite wave velocity of seismic signals and calculates the relative travel time delay of signals between all possible station pairs. In a grid search procedure, all potential locations (raster pixels) are tested for their potential time delays for the same station pairs. The final source location is provided as a density function of the average difference between empirical and pixel-specific potential time delay. The signal migration routine was based on the deconvolved, $10-20 \mathrm{~Hz}$ filtered, tapered signal envelopes. Only events with a signal-to-noise ratio (SNR) greater than 3 and recorded by at least three stations were located, using the apparent seismic wave velocity as constrained by the active seismic survey (see below). The resulting location estimates were truncated to values greater than the quantile $q_{0.99}$, a usual value to define the range of location uncertainty, approximately 10-20\% of the inter-station distance (e.g., Dietze et al., 2017) .

The average apparent seismic wave velocity was determined by the active seismic survey. The time differences between blows as recorded on the closest station and all other stations were determined by cross correlation of the signal envelopes and converted to a velocity using the distance of each station to the one closest to the hammer blows. 


\section{Results}

\subsection{Mapped redd locations}

During the study period, surveyors identified a total of four completed redds within the study reach (Fig. 1 a): redd no. 1 was mapped by 08 May, redd no. 2 by 13 May and redds no. 3 and no. 4 by 23 May. All new redds identified during the study period were within $5 \mathrm{~m}$ of the left bank. In addition, redd no. 2 showed signs of some fresh digging in between survey dates as the flag we used to mark it had been slightly covered up with fresh sediment. Redd size, shape and sediment composition (coarse gravel and cobbles) were consistent characteristics from other steelhead spawning sites (S. P. Gallagher et al., 2007).

\subsection{Environmental conditions during experiment}

During the first half of the survey period, the Mashel River showed a steadily decreasing discharge with minor diurnal fluctuations (Fig. 1 b). From 15 May until the end of the study period, there were several multi-hour long periods of rain, causing distinct flashy peaks of the river discharge. The rain events were visible in the seismic spectra (Fig. $1 \mathrm{~b}$ ) as broadband bursts of high energy. The sub-minute resolution of the seismic data also showed that the rain events did not cover an entire day but only a few hours. The seismic waveforms further showed the typical signature of repeated raindrop impacts: numerous $<0.2$ s long single 20-200 Hz pulses (cf. Dietze et al., 2017). The rain-driven high flows did not show up visually in the seismic spectrogram, neither as a clear power increase of the persistent $25-50 \mathrm{~Hz}$ band nor as a prominent broadband $(20-70 \mathrm{~Hz})$ signal indicative of bedload transport (cf. Fig. 2 b and Dietze, Lagarde, et al. (2019)). Likewise, we saw no indications of recent over bank flooding conditions during our site visits.

\subsection{Artificial redd-building signal properties}

The seismic signatures of our three artificial redd-building experiments (Fig. 2) showed the effects of the applied mechanisms. Type 1 (fin movement causing pebble agitation) and type 2 (moving sediment with boot) both generated seismic signals more than 10 $\mathrm{dB}$ above background, peaking at 25-40 Hz (Fig 2 a). However, the type 2 mechanism generated a stronger broadband signal overall, approximately $7-8 \mathrm{~dB}$ higher than type 1 between 50 and $150 \mathrm{~Hz}$. The type 3 mechanism (contactless pebble agitation with stiff paddle) only marginally exceeded the background level (blue versus grey curve in Fig. 2 a). Overall, all three agitation types show similar spectral peaks as the background signal space.

We seismically located distinct amplitude peaks in the signal sequences to test how well the positions of artificial redd-construction activities can be estimated. Locations of the sequences of three hits with a hammer onto a boulder prior to the actual redd experiments (Fig. $2 \mathrm{c}$ ) deviated from the true site by $3.0_{-0.2}^{+0.4} \mathrm{~m}$ (median and quartile range). Two randomly chosen 2-3 s intervals during the type 1 and type 2 redd-construction experiments could also be located with deviations $2.5_{-0.3}^{+0.1} \mathrm{~m}$. For the hammer blow signals, we were able to use a narrow filter frequency window of $16-20 \mathrm{~Hz}$, focusing on frequencies below the river induced signals (Fig. 2 b). For the weaker redd-building experiment signals, we needed to use a wider frequency window of $16-25 \mathrm{~Hz}$ to allow for a sufficient signal to noise ratio. The active seismic survey yielded an apparent seismic wave velocity of $350 \pm 40 \mathrm{~m} / \mathrm{s}$. We used the average value for further analyses. For details on the results see the SI. 

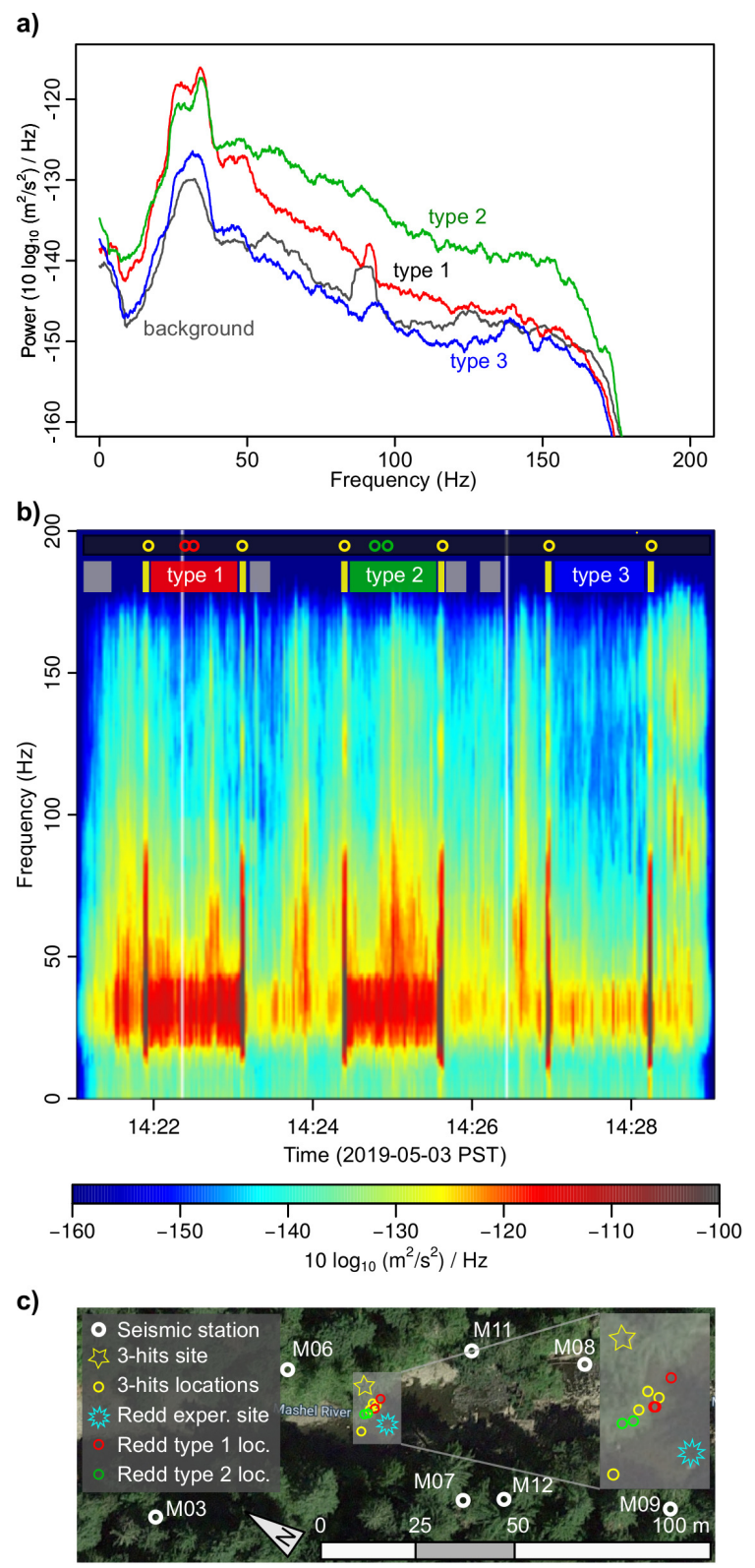

Figure 2. Artificial redd construction experiment signatures. a) Seismic spectra of the three different redd-building approaches and background spectrum. Colour code also used in other panels. b) Spectrogram of the full artificial redd-building sequence, recorded by station M07. Note how three hits with a cobble on a boulder (yellow bars in top part legend) initiate the actual experiments (red, green and blue bars denoting the three types). Dots above top legend indicate time sections used for location of signals. c) Location results of selected event periods as denoted in b). Inset shows enlarged version of the location results. Experiment start and end times were indicated by three hits on a boulder located as indicated by yellow star. The redd-building experiment locations are indicated by the blue star and the seismic location results are depicted by coloured circles. 


\subsection{Event signal characteristics}

The STA-LTA routine yielded several thousand potential events, of which most were rejected automatically. We manually checked the remaining 591 potential events using the software Snuffler. These checks were based on a joint observation of the signals recorded by stations closest to the independently mapped redd locations (M07, M08, M10, M11 and M12), as well as spatially adjacent stations if these helped to clarify expected amplitude reductions and signal arrival time delays with increasing spatial distance from the potential source.

Checks included the criteria defined in section 3. We checked the properties of individual seismic pulses, including durations, amplitudes and amplitude differences, the pauses between the pulses, and the evolution of pulse properties throughout the entire duration of a potential redd-building signature, which is composed of a series of individual pulses. Most individual signals were clearly visible above background at 3-4 stations, depending on the amplitudes of individual pulses (see for example Fig. $3 \mathrm{~b}$ ). Whenever possible (i.e., a viable signal was recorded by at least three stations), we located the seismic source of individual pulses and rejected a pulse sequence if at least $10 \%$ of the visible pulses could not be located consistently at the same position within the river channel (i.e., overlapping location estimates within the $99 \%$ polygon). In total, we identified 45 potential redd-building signal sequences from 29 April through 27 May.

We use one example period (Fig. 3) to illustrate the characteristics of signals indicative of redd-building activities (Fig. 4). After several hours without any short-pulsed signals, station M11 recorded a series of 256 mostly high-amplitude signals $( \pm 50 \mu \mathrm{m} / \mathrm{s})$, lasting $0.33_{-0.11}^{+0.13} \mathrm{~s}$ each. The entire phase lasted approximately $12 \mathrm{~min}$ and exhibited four discrete activity clusters. Each cluster, which consisted of 50 to 100 individual pulses, lasted approximately 2 to 3 min, separated by pauses of roughly the same duration (Fig. 4 a). There were no consistent trends of seismic amplitude with time, neither during clusters nor throughout the entire sequence. The sequence was recorded at 10:10 PST time. Seismic location estimates of those signal sources that were distinctive from at least three seismic stations (Fig. $3 \mathrm{c}$ and d) point consistently to a region within the river channel, approximately five to ten metres upstream of station M11, with an average deviation from the independently mapped redd location of $8 \mathrm{~m}$ (excluding one outlier, orange dot in Fig. $3 \mathrm{~d}$ ).

We also found similar results, with most of the above-mentioned characteristics of clusters of pulses, for the other potential redd-building signals (Tab. 1). These other events usually lasted several minutes. They either exhibited two to five clusters of broadband seismic pulses, each lasting less than a second, or showed a continuous though non-rhythmic occurrence of individual pulses. Those events that were suitable for estimating their source location (i.e., signals recorded by at least three stations above background noise level) all resulted from activity within the river channel. However, the location uncertainty makes any more precise links to independently mapped redd buildings unreliable. In all cases, the seismic location estimates showed higher uncertainties (e.g., $22 \mathrm{~m}$ on average for redd no. 1, based on signals recorded for more than 10 min on 2019-05-06 19:23 PST) than the artificial experiments (Fig. 2) and the results for redd no. 2 (Fig. 3).

The seismic records also exhibited signals that were not straightforward to associate with redd-building activity. One such type of signal sometimes occurred for extensive time periods; two hours on 20 May 18:30 PST and ten hours on 21 May 07:30 PST (Fig. 5 a). The signals show similar properties as noted above for the example event (Fig. 3): short, discrete, broad band pulses, forming clusters of up to ten pulses, which were separated by several seconds of calmness. The signals were visible on at least three stations (M11, M10, M08) and could in many cases be located around redd no. 4 (Fig. 1).

Another outstanding, recurring signal pattern was repeatedly recorded at station M11 (Fig. 5 b). A total of 32 such events were observed throughout the instrumented 

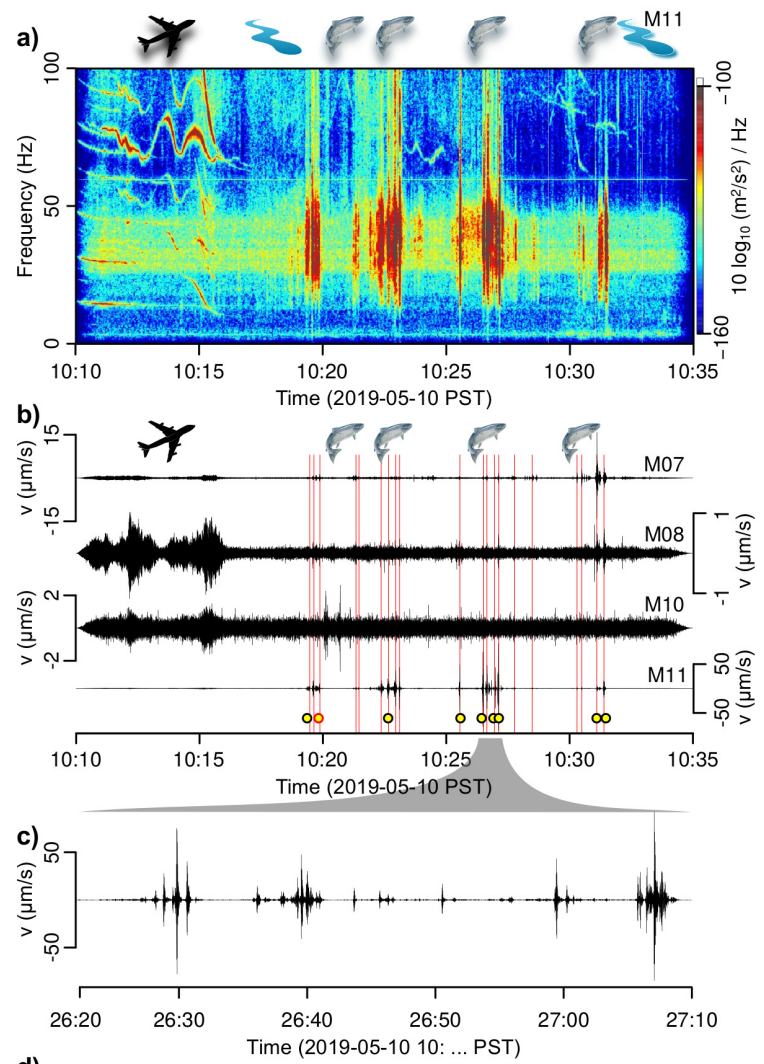

d)

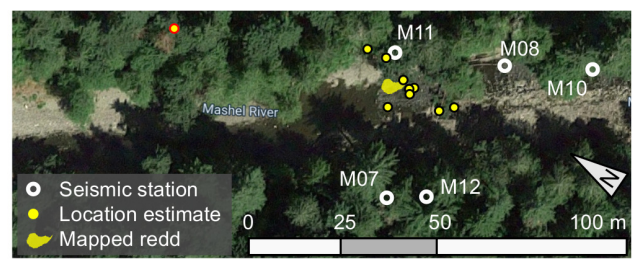

e)

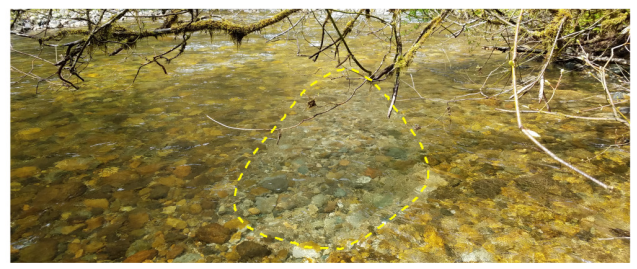

Figure 3. Seismically constrained salmonid redd activity. a) Spectrogram from station M11 showing example of plane signature as harmonic tremor (17:10-17:15 PST) and clusters of short broadband pulses (17:19-17:33 PST). Note the continuous frequency band at 30-50 Hz due to river discharge. b) Seismic waveforms of four close-by stations. Red vertical lines allow comparing the joint timing of redd-building signals at different stations. Yellow dots depict signals used for location estimates. Dot with red outline is outlier in d). c) Close-up of one redd-building cluster with a sequence of short pulses due to tail movements of steelhead. d) Seismic source location map of the signals indicated in b). e) Picture of the redd created between 8-13 May. The reworked area is indicated by the dashed yellow line. 
a)

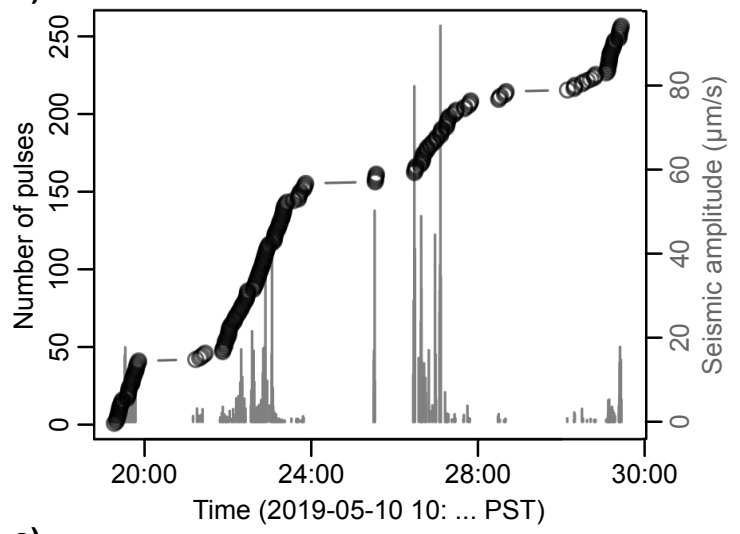

c)

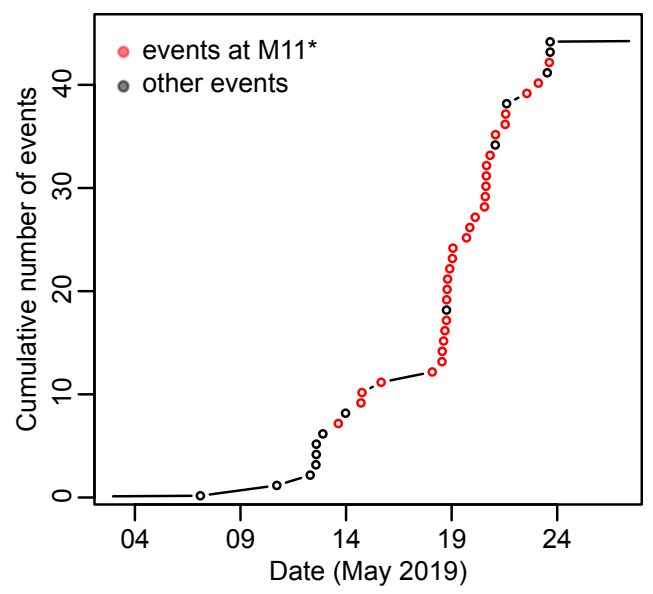

b)

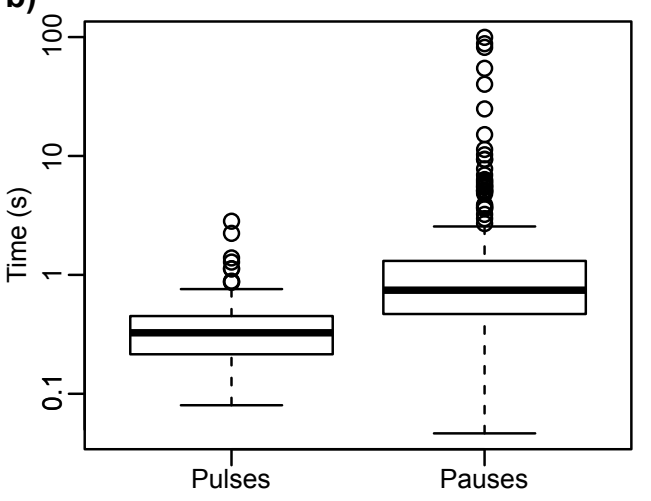

d)

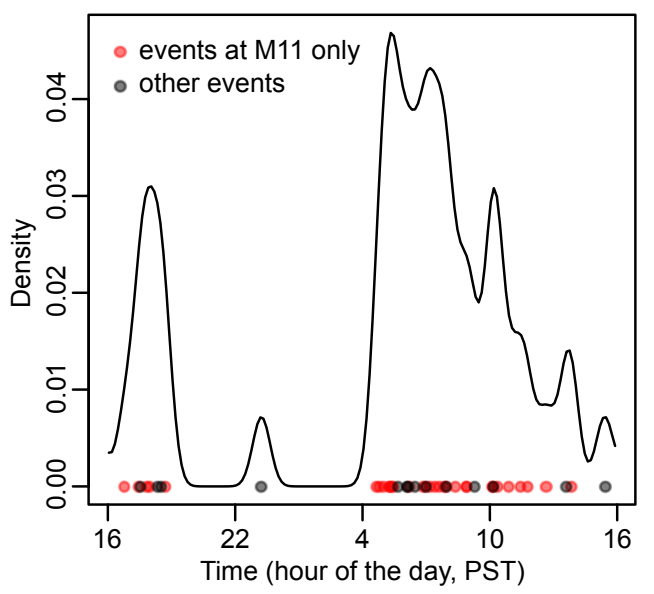

Figure 4. Characteristics of redd-building pulses and events. a) Cumulative number of individual pebble agitation pulses with time for example event from Fig. 3. b) Box plots of pulse duration and inter-pulse periods as measured at the closest seismic station. c) Cumulative number of redd-building events throughout entire survey period. d) Distribution of signal occurrence at the diurnal scale, shown as kernel density estimate plot (kernel size $16 \mathrm{~min}$ ). 
Table 1. Summary of identified seismic events (potentially) associated with redd-building activities. Seismic locations (easting and northing in UTM coordinates, signals filtered between 10 and $20 \mathrm{~Hz}$ throughout) are only provided when an event was clearly recorded by at least three stations. Stations with maximum seismic amplitude $\left(A_{\max }\right)$ indicate station most proximal to the potential seismic source. Index ${ }^{1}$ denotes events only recorded at station M11, cf. Fig. 5 b. Potential redd ID refers to IDs as shown in Fig. 1.

\begin{tabular}{|c|c|c|c|c|c|c|}
\hline Event & Start time (PST) & Duration (s) & Easting $(\mathrm{m})$ & Northing (m) & Station $A_{\max }$ & Redd ID \\
\hline 1 & 2019-05-06 19:23:00 & 600 & NA & NA & & 1 \\
\hline 2 & 2019-05-10 10:17:00 & 900 & NA & NA & M11 & 2 \\
\hline 3 & 2019-05-12 00:15:00 & 60 & 551217 & 5188989 & M12 & 1 \\
\hline 4 & 2019-05-12 06:42:35 & 125 & 551214 & 5189017 & M11 & 2 \\
\hline 5 & 2019-05-12 07:07:30 & 620 & 551227 & 5189019 & M11 & 2 \\
\hline 6 & 2019-05-12 07:10:00 & 1800 & $\mathrm{NA}$ & NA & M11 & 2 \\
\hline 7 & 2019-05-12 14:37:10 & 270 & 551220 & 5189006 & M12 & 4 \\
\hline 8 & 2019-05-13 08:11:00 & 300 & NA & NA & $\mathrm{M} 11^{1}$ & NA \\
\hline 9 & 2019-05-13 04:25:40 & 400 & 551219 & 5189008 & M07 & 3 \\
\hline 10 & 2019-05-14 09:54:00 & 300 & NA & NA & $\mathrm{M}_{1}{ }^{1}$ & $\mathrm{NA}$ \\
\hline 11 & 2019-05-14 11:08:00 & 300 & NA & NA & $\mathrm{M}_{1}{ }^{1}$ & NA \\
\hline 12 & 2019-05-15 08:52:00 & 100 & NA & NA & $\mathrm{M}_{1}{ }^{1}$ & NA \\
\hline 13 & 2019-05-17 19:01:00 & 100 & NA & NA & $\mathrm{M}_{1}{ }^{1}$ & NA \\
\hline 14 & 2019-05-18 06:02:00 & 300 & NA & NA & ${\mathrm{M} 11^{1}}^{1}$ & NA \\
\hline 15 & 2019-05-18 06:19:00 & 300 & NA & NA & ${\mathrm{M} 11^{1}}^{1}$ & NA \\
\hline 16 & 2019-05-18 07:53:00 & 300 & NA & NA & $\mathrm{M}_{1}{ }^{1}$ & NA \\
\hline 17 & 2019-05-18 09:23:00 & 200 & NA & NA & $\mathrm{M}_{1}{ }^{1}$ & NA \\
\hline 18 & 2019-05-18 11:06:00 & 400 & NA & NA & $\mathrm{M}_{1}{ }^{1}$ & NA \\
\hline 19 & 2019-05-18 11:09:38 & 60 & 551228 & 5188999 & M08 & 4 \\
\hline 20 & 2019-05-18 11:21:00 & 200 & NA & NA & ${\mathrm{M} 11^{1}}^{2}$ & NA \\
\hline 21 & 2019-05-18 11:52:00 & 200 & NA & NA & ${\mathrm{M} 11^{1}}^{2}$ & NA \\
\hline 22 & 2019-05-18 12:25:00 & 200 & NA & NA & ${\mathrm{M} 11^{1}}^{2}$ & NA \\
\hline 23 & 2019-05-18 14:51:00 & 300 & NA & NA & ${\mathrm{M} 11^{1}}^{2}$ & NA \\
\hline 24 & 2019-05-18 17:50:00 & 300 & NA & NA & ${\mathrm{M} 11^{1}}^{1}$ & NA \\
\hline 25 & 2019-05-18 18:30:00 & 200 & NA & NA & ${\mathrm{M} 11^{1}}^{1}$ & NA \\
\hline 26 & 2019-05-19 09:54:00 & 200 & NA & NA & $\mathrm{M}_{1} 1^{1}$ & NA \\
\hline 27 & 2019-05-19 13:40:00 & 200 & NA & NA & ${\mathrm{M} 11^{1}}^{1}$ & NA \\
\hline 28 & 2019-05-19 19:45:00 & 1000 & NA & NA & M11 ${ }^{1}$ & NA \\
\hline 29 & 2019-05-20 06:19:00 & 300 & NA & NA & $\mathrm{M}_{1} 1^{1}$ & NA \\
\hline 30 & 2019-05-20 07:14:00 & 200 & NA & NA & $\mathrm{M}_{1} 1^{1}$ & NA \\
\hline 31 & 2019-05-20 07:59:00 & 300 & NA & NA & $\mathrm{M}_{1}{ }^{1}$ & NA \\
\hline 32 & 2019-05-20 08:25:00 & 200 & NA & $\mathrm{NA}$ & $\mathrm{M}_{1}{ }^{1}$ & NA \\
\hline 33 & 2019-05-20 08:38:00 & 600 & NA & NA & $\mathrm{M}_{1} 1^{1}$ & NA \\
\hline 34 & 2019-05-20 12:45:00 & 200 & NA & NA & $\mathrm{M}_{1}{ }^{1}$ & NA \\
\hline 35 & 2019-05-20 18:35:00 & 7500 & NA & NA & M12 & 4 \\
\hline 36 & 2019-05-20 18:53:00 & 300 & NA & NA & $\mathrm{M}_{1} 1^{1}$ & NA \\
\hline 37 & 2019-05-21 05:50:00 & 900 & $\mathrm{NA}$ & NA & $\mathrm{M} 11^{1}$ & NA \\
\hline 38 & 2019-05-21 06:25:00 & 200 & NA & NA & $\mathrm{M} 11^{1}$ & NA \\
\hline 39 & 2019-05-21 07:30:00 & 36000 & NA & NA & M12 & 4 \\
\hline 40 & 2019-05-22 06:29:00 & 600 & NA & NA & $\mathrm{M}_{1}^{1}$ & NA \\
\hline 41 & 2019-05-23 05:42:00 & 600 & NA & NA & $\mathrm{M}_{1}{ }^{1}$ & NA \\
\hline 42 & 2019-05-23 08:01:00 & 200 & NA & NA & M07 & 3 \\
\hline 43 & 2019-05-23 08:58:00 & 60 & NA & NA & ${\mathrm{M} 11^{1}}^{1}$ & NA \\
\hline 44 & 2019-05-22 19:33:00 & 90 & 551225 & 5188995 & M08 & 4 \\
\hline 45 & 2019-05-23 08:57:00 & 120 & 551219 & 5188984 & M12, M11 & 4 \\
\hline
\end{tabular}



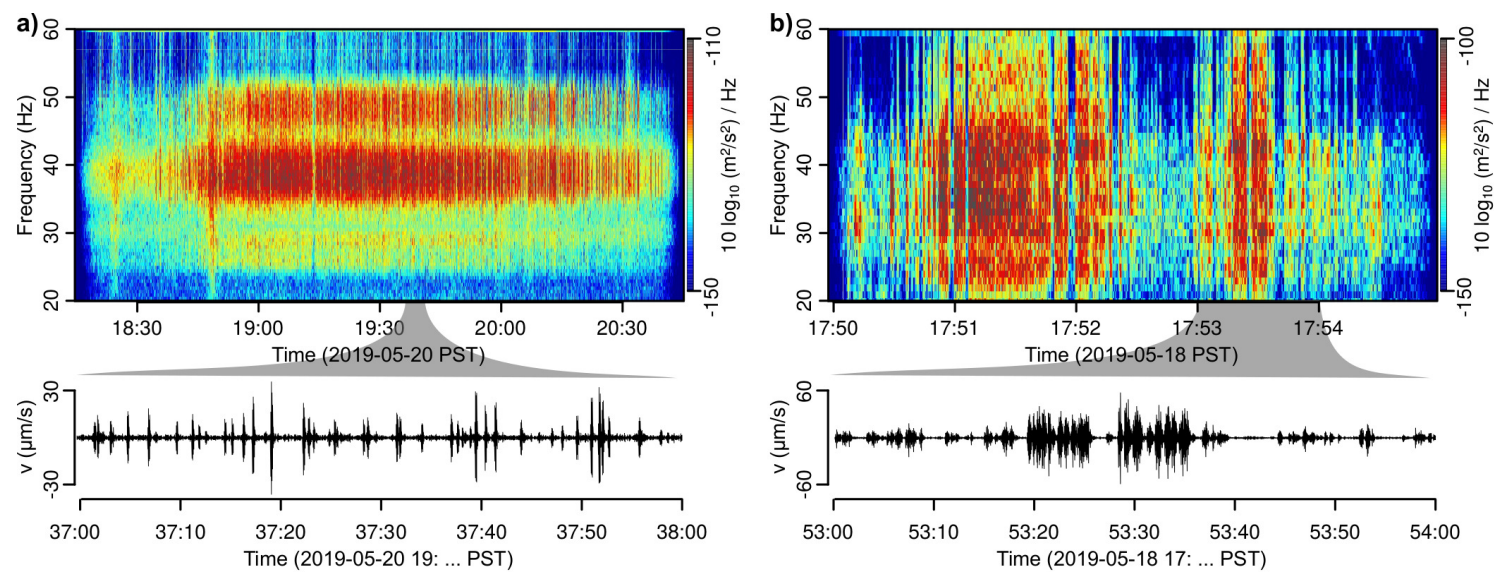

Figure 5. Seismic spectrograms and waveforms of additional signals recorded during the survey period. a) A two-hour long activity period characterised by short period $25-55 \mathrm{~Hz}$ pulses, most prominently recorded by station M12. b) Example of recurring activity periods with similar properties as shown in a) or Fig. 3, recorded at station $\mathrm{M} 11^{1}$.

period. Signal properties were in general similar to the other events from Tab. 1. However, the seismic amplitudes were 20-30\% weaker than the signals from Fig. 3; although the signals were clearly visible at station M11, the signals were not distinct from background noise levels at the other stations. Accordingly, it was not possible to estimate the location of their sources.

\section{Discussion}

\subsection{Proof of concept}

We demonstrate the potential of a seismic approach for identifying the spatial and temporal patterns of redd-building activity using two independent approaches - comparing seismic data collected during construction of man-made artificial redds and during construction of redds by a native, wild salmonids. The artificially-induced signals (manmade redds, Fig. 2) showed major spectral overlap with the frequency window of the riverinduced seismic signature (Dietze, Lagarde, et al., 2019; Gimbert et al., 2014) and only type 1 and 2 agitation yielded a seismic signal sufficiently different from background noise (Fig. 2 a). This complements our work demonstrating the ability of our seismic approach to detect four redds created by steelhead in the natural setting.

The links between seismic data and manually mapped redds are based on both joint time windows, and seismic source location estimates matching with mapped locations. These links, although robust, open up room for interpretation, predominantly because of the large mapping time intervals, and to a lesser degree because of the spatial uncertainty of the seismic location estimate. Thus, future work should be focused on further validation of seismic signal inferences of salmonid redd construction over a variety of species and spatial/temporal scales. Whenever a location for the events from Tab. 1 was possible, it pointed at a seismic source inside the river. This already rules out any potential terrestrial causes for the measured signals. Although signals such as those from Fig. 3 could in principle be generated by animals like woodpeckers, the location constraint does not support such a hypothesis. Likewise, spatially mobile seismic sources, such as persons wading the river or animals passing a seismic station outside the river, would stand in conflict with the stable seismic location results and the lack of systematic increases and decreases of seismic amplitudes at a given seismic station. Other signals from in- 
side the river but not related to fish activity might be river bedload transport. However, studies from rivers in different settings, from sand- to gravel- and even boulder-beds channels and from flash-flood dominated to continuously active (Polvi et al., in review; Dietze, Lagarde, et al., 2019; Dietze, Gimbert, et al., 2019; Burtin et al., 2016) consistently showed that bedload transport results in overall increased amplitudes of the seismic signals of certain frequencies and not in the emergence of erratic short seismic pulses. Furthermore, the seismic spectrogram of the entire study period (Fig. 1 b) did now show any indications of sustained bedload movement during the rain-driven high flow events. Finally, rain drop impacts can be excluded as an explanation of the seismic pulses from Fig. 3 or Fig. 5 because these seismic pulses (which were recorded by at least three stations) provided location estimates within the river channel. Thus, we propose that the seismic signals we report here were indeed caused by biotic activity within the river channel, more specifically by steelhead actively redistributing river bed material.

The redd-construction signal example illustrated in Fig. 3 showed that redd-building signals could be recorded up to a distance of at least $50 \mathrm{~m}$ (distance between redd no. 1 and station M10) and yield very clear signals (signal-to-noise-ratio > 40) at distances of less than $10 \mathrm{~m}$ (e.g., M07, M11). The artificially-induced signals that generated sufficient seismic energy could be located, using the migration technique, with deviations of less than five metres on average. This sets the location precision baseline for any other internal river location exercises. While high location precision may be less important when the goal is simply to detect when, how and how long redd building activity occurs, this feature becomes essential when the goal is to map out individual redd buildings and their evolution with time. Given a river width of $25 \mathrm{~m}$ and an average distance between four mapped redds of $20.4_{-5.3}^{+7.7} \mathrm{~m}$, the seismic method allows for sufficient accuracy to discriminate between different redds; however, this is a tentative estimate based on the small number of samples. The location estimate could be improved in subsequent surveys by i) using a denser station network (less than $10 \mathrm{~m}$ station spacing), ii) sampling the signals by more than $400 \mathrm{~Hz}$, a recording frequency which allows no more than approximately one meter accuracy in this environment when using the arrival time-based migration approach to locating seismic sources, and iii) reducing the noise background, for example by burying the sensors. A drawback of this study design was that the geophones were not buried but installed on the ground. This resulted in many spurious event detections that ultimately turned out to be plane crossings (Fig. 3 a). Likewise, stations more than $50 \mathrm{~m}$ away from the banks (results not shown) did not record any of the signals registered by the network compartments close to the stream.

\subsection{Redd building anatomy}

For over a century, biologists and fisheries managers have contemplated the spawning behaviour of salmonids. For species that spawn more than once, and therefore benefit from surviving post spawning, the mating behaviour and associated redd-building activities are often elusive and thought to take place in the evening hours. However, a small number of studies have documented spawning of steelhead and other species occurring during daylight hours. The current study sheds light on this data gap and suggests that the majority of spawning for steelhead trout takes place during daylight hours and is focused around the crepuscular period. For steelhead, there is likely a trade-off between attracting a mate, avoiding predation and metabolic demands associated with spawning that may be tied to stream temperature. Needham and Taft (1934) recorded short periods of digging prior to spawning followed by additional short periods of digging to bury recently expelled and fertilized eggs. This was then repeated one or more times at the same site across multiple days (and possibly nights). Our passively recorded measurements of gravel transport associated with spawning are in agreement with the observations of Needham and Taft (1934) and take the spawning description one step further by describing the event at a much finer scale and highlighting the importance of the crepuscular period for spawning. Specifically, at the diurnal scale, redd-building 
activity in the current study showed a distinct pattern (Fig. 4 d). The majority of reddbuilding signals occurred between early morning and noon local time (i.e., 05-13 PST), with a focused onset and a slowly receding rate. A secondary cluster emerges in the evening (i.e., 17-20 PST). There are no significant differences between the repeated events only recorded at station M11 (Fig. 5 b) and the other events. We interpret this diurnal pattern as preferred fish activity during daytime but avoiding the middle of the day with highest temperatures and direct sunlight. It remains unclear if these long activity periods, lasting several hours, are typical for steelhead across the range. With a protracted spawning period occurring over more than 4 months, steelhead lend themselves to additional work that collects information across a greater number of spawners. Additionally, focusing this work on semelparous species that have a less flexible spawning window may provide insight into how different life history strategies shape spawning behaviour.

This work resulted in a dramatic improvement in the understanding of spawning behaviour of steelhead and paves the way for improved tools to monitor salmonids and the effects they have on the hydraulic and sedimentological characteristics of a stream. In addition, this first attempt at applying seismic monitoring to fisheries management highlight important next steps to fine tune this work. The duration of a steelhead spawning event in this study averaged 6 days. About $90 \%$ of spawning took place during daylight hours (07-18 PST), and $60 \%$ of spawning behaviour took place in morning hours before noon (Fig. 4 c).

It has been shown that the process of building a redd can take several days for steelhead, including both the stage before and the stage after the spawning phase (Needham \& Taft, 1934; Burner, 1951; Fuchs \& Caudill, 2019). Thus, one single sequence of pulses lasting 10-20 min will certainly not be enough to create a proper redd, and it is to be expected that there must be additional and extensive seismic redd-building signals. For redd no. 2 (Fig. 1 a, Tab. 1), there were four discrete pulse sequences with a location matching a surveyed redd. In addition, there is the day-long, repeated occurrence of several minute-long sequences that were only visible at station M11 which is closest to redd no. 2. In principle, these findings could be interpreted as the seismic signature of the full redd-building, spawning and redd-finalisation process, in agreement with previous data (Burner, 1951; Gottesfeld et al., 2004). Particularly given that during an 11-day period we were able to detect indications of activity located at or near all of the independently mapped redd locations. However, without more robust location information, this remains tentative, especially for redd locations so close together in space. For instance, redds no. 3 and no. 4 could perhaps be linked with several repeated seismic activity clusters between 12 and 23 May given the close proximity where these spawning events took place. However, a robust seismic location estimate would be needed to properly support this interpretation and would be recommended for future work.

\subsection{Perspectives}

Based on previous experience with seismic sensors to detect and quantify fluvial sediment transport dynamics (Dietze, Lagarde, et al., 2019; Polvi et al., in review), the boundary conditions for a functional seismic network were determined. Given the general success of the seismic approach to detect and quantitatively describe the process of redd building, we propose objectives and strategies of subsequent research in that direction. 1) A longer instrumentation time is required to survey the full spawning season. This requires rethinking logistics of power provision and station maintenance. 2) The network layout, which was designed in this study to account for a hitherto unknown type of seismic source, should be optimised. At a minimum, this means that there is no need to deploy stations far away from the banks. Rather, stations should be set up close to the banks, at distances of less than $10 \mathrm{~m}$ from each other. In addition, the sensors should be deployed below the surface to reduce signal contamination by sources such as air traffic and weather phenomena. 3) An active seismic survey covering the entire reach to be 
monitored proved essential to constrain the seismic wave velocity, required for robust source location estimates. Further seismic details can be provided by estimating the seismic energy emitted by the fish activity, which can be interpreted as an equivalent of kinetic energy. For this step, one could use existing laws to relate seismic amplitudes as recorded by several stations to the amplitude at the located source (e.g. Burtin et al., 2016). 4) Fundamentally, a future study would benefit from more independent confirmation data. These could be provided by time lapse imagery on sub areas of the surveyed reach, detailed mapping of (previously seismically detected and located) redds to check to which extent these redds have been modified between mapping surveys, and how much material has been mobilised and redistributed. Finally, 5) utilisation of automatic approaches to redd building event detection would be essential to reduce the amount of manual workload. Machine learning solutions open promising avenues in this regard, especially since the unique properties of the signals identified by us (rhythmic short pulses of similar spectral patterns from inside the stream) could be easily translated into features, required for seismic event classification (e.g. Hibert et al., 2017).

\section{Conclusions}

We successfully tested a new method to survey a fundamentally important phenomenon in river ecology as well as fluvial geomorphology: salmonid redd-building activity in gravel-bed rivers. The seismic approach can be highly complementary to the range of methods classically employed. Furthermore, in many regions, visual surveying of redds is not possible because of, for example, low visibility due to high turbidity or humic water, difficult to distinguish redds due to dark-coloured sediment, and deep water. Therefore, the seismic method would allow data on redd-building to be collected for the first time in many regions (e.g., northern Europe). It also allows for continuous monitoring regardless of environmental conditions, providing high-resolution insight into the dynamics of redd-building, from minute-long excavation activity clusters to the kinetics of individual pebble agitation pulses, and it allows estimates of the location of these individual pulses. Based on these detailed data, we found that excavation appears to occur preferentially during daytime, starting in the early morning, with a pause in the middle of the day and another peak in the late afternoon, with almost no activity during the night. Individual activity pulses of bed material agitation, lasting less than a second and forming clusters of 50 to 100 pulses are separated by minute-long pauses - a pattern that is in agreement with results from other studies on the redd-building process. The decisively generic network design showed that in future studies, stations should be deployed linearly along both banks in order to optimise the detection and location quality.

In addition to learning more about spawning behavior, this study can open doors to understanding geomorphic change by salmonids. While seasonal sediment transport by salmonids has been quantified, with seismological methods, we can make more precise calculations of sediment flux (Dietze et al. 2019), clearly partitioned between fluvial and biological processes. Seismic location estimates of redd-building signals can allow a better understanding of potential sub-reach morphologic effects of spawning. Moreover, the approach would not be restricted to redd building activity, but could be generalised to further biological agents that actively move sediment particles, given that the seismic signature of their activity is distinct enough to be detected and attributed to the animal under focus. Thus our results provide a methodology with the potential to address large unanswered questions about ecosystem engineers and bioturbators (Polvi \& Sarneel, 2018), including effects on smaller and larger spatial scales than traditionally measured.

\section{Acknowledgments}

We thank the following for assistance in the field, with set-up, geomorphic measurements, and redd surveys: Annika Holmgren and Gustav Hellström with the Swedish University 
of Agricultural Sciences and Gabe Madel, Riley Freeman and Steve Boessow with the Washington Department of Fish and Wildlife. We thank the Geophysical Instrument Pool Potsdam (GIPP) for provision of the seismic stations.

\section{Data availability statement}

The raw seismic data are available under the DOI 10.5880/GFZ.4.6.2020.004 (Dietze et al., 2020). The SI contain all code and information necessary to reproduce the results of this study. All other data is available from the public resources as referenced in the text.

\section{References}

Allen, R. (1982). Automatic phase pickers: Their present use and future prospects. Bulletin of the Seismological Society of America, 72, S225-S242.

Berejikian, B., Johnson, T., Endicott, R., \& Lee-Waltermire, J. ～(2008). Increases in steelhead (oncorhynchus mykiss) redd abundance resulting from two conservation hatchery strategies in the hamma hamma river, washington. Canadian Journal of Fisheries and Aquatic Sciences, 65(4), 754-764. doi: 10.1139/F08-014

Bourbie, T., Coussy, O., \& Zinszner, B. (1987). Acoustics of porous media. Gulf Publishing Company.

Burner, C. J. (1951). Characteristics of spawning nests of columbia river salmon. US Department of the Interior.

Burtin, A., Hovius, N., \& Turowski, J. M. (2016). Seismic monitoring of torrential and fluvial processes. Earth Surface Dynamics, 4, 285-307. doi: 10.5194/esurf $-4-285-2016$

de Oliveira Frascá, M. H. B., \& Del Lama, E. A. (2018). Biological weathering. In P. T. Bobrowsky \& B. Marker (Eds.), Encyclopedia of engineering geology (pp. 61-62). Springer International Publishing. doi: 10.1007/978-3-319-73568-9_29

Dietze, M. (2018a). 'eseis' - an $R$ software toolbox for environmental seismology. $v$. 0.4.0. GFZ Data services. doi: http://doi.org/10.5880/GFZ.5.1.2018.001

Dietze, M. (2018b). The R package "eseis" - a software toolbox for environmental seismology. Earth Surface Dynamics, 6, 669-686. doi: 10.5194/esurf-6-669 $-2018$

Dietze, M., Gimbert, F., Turowski, J., Stark, K., Cadol, D., \& Laronne, J. (2019). The seismic view on sediment laden ephemeral flows - modelling of ground motion data for fluid and bedload dynamics in the arroyo de los piños [Computer software manual]. Retrieved from http://micha-dietze.de/pages/ publications/other/Dietze_et_al_2019b.pdf (Paper to SEDHYD conference)

Dietze, M., Lagarde, S., Halfi, E., Laronne, J. B., \& Turowski, J. M. (2019). Joint sensing of bedload flux and water depth by seismic data inversion. Water Resources Research, 55(11), 9892-9904. doi: 10.1029/2019WR026072

Dietze, M., Losee, J., Polvi, L., \& Palm, D. (2020). Seismic data from a project on monitoring of salmonid nest building, Mashel River, USA, v. 0.1.0. GFZ Data services. doi: http://doi.org/10.5880/GFZ.4.6.2020.004

Dietze, M., Mohadjer, S., Turowski, J., Ehlers, T., \& Hovius, N. (2017). Validity, precision and limitations of seismic rockfall monitoring. Earth Surface Dynamics, 2017, 1-23. doi: 10.5194/esurf-2017-12

Field-Dodgson, M. (1987). The effect of salmon redd excavation on stream substrate and benthic community of two salmon spawning streams in canterbury, new zealand. Hydrobiologia, 154, 3-11. doi: 10.1007/BF00026826

Fremier, A. K., Yanites, B. J., \& Yager, E. M. (2018). Sex that moves mountains: The influence of spawning fish on river profiles over geologic timescales. 
Geomorphology, 305, 163 - $172 . \quad$ (Resilience and Bio-Geomorphic Systems Proceedings of the 48th Binghamton Geomorphology Symposium) doi: https://doi.org/10.1016/j.geomorph.2017.09.033

Fuchs, N., \& Caudill, C. (2019). Classifying and inferring behaviors using realtime acceleration biotelemetry in reproductive steelhead trout (Oncorhynchus mykiss). Ecology and Evolution, 9, 11329-11343. doi: 10.1002/ece3.5634

Gallagher, S., \& Gallagher, C. (2005). Discrimination of chinook salmon, coho salmon, and steelhead redds and evaluation of the use of redd data for estimating escapement in several unregulated streams in northern california. North American Journal of Fisheries Management, 25(1), 284-300. doi: 10.1577/M04-016.1

Gallagher, S. P., Hahn, P. K. J., \& Johnson, D. H. (2007). Redd counts. $\quad$ In D. H. Johnson et al. (Eds.), Salmonid field protocols handbook: techniques for assessing status and trends in salmon and trout populations (pp. 197-234). Bethesda, Maryland: American Fisheries Society.

Gimbert, F., Tsai, V., \& Lamb, M. (2014). A physical model for seismic noise generation by turbulent flow in rivers. Journal of Geophysical Research, 119, 22092238. doi: 10.1002/2014JF003201

Gottesfeld, A. S., Hassan, M. A., Tunnicliffe, J. F., \& Poirier, R. W. (2004). Sediment dispersion in salmon spawning streams: The influence of floods and salmon redd construction1. JAWRA Journal of the American Water Resources Association, 40(4), 1071-1086. doi: 10.1111/j.1752-1688.2004.tb01068.x

Harvey, G. L., Henshaw, A. J., Brasington, J., \& England, J. (2019). Burrowing invasive species: An unquantified erosion risk at the aquatic-terrestrial interface. Reviews of Geophysics, 57(3), 1018-1036. doi: 10.1029/2018RG000635

Hassan, M. A., Gottesfeld, A. S., Montgomery, D. R., Tunnicliffe, J. F., Clarke, G. K. C., Wynn, G., ... Macdonald, S. J. (2008). Salmon-driven bed load transport and bed morphology in mountain streams. Geophysical Research Letters, 35(4). doi: 10.1029/2007GL032997

Heimann, S., Kriegerowski, M., Isken, M., Cesca, S., Daout, S., Grigoli, F., ... Dahm, T. (2017). Pyrocko - an open-source seismology toolbox and library. GFZ Data services. doi: http://doi.org/10.5880/GFZ.2.1.2017.001

Hibert, C., Provost, F., Malet, J.-P., Maggi, A., Stumpf, A., \& Ferrazzini, V. (2017). Automatic identification of rockfalls and volcano-tectonic earthquakes at the piton de la fournaise volcano using a random forest algorithm. J. Volcanol. Geotherm. Res., 340, 130-140. doi: 10.1016/j.jvolgeores.2017.04.015

IRIS. (2017). Incorporated research institutions for seismology - using sac. Available at ds.iris.edu/ (2017/12/16).

Losee, J. P., Phillips, L., \& Young, W. C. (2016). Spawn timing and redd morphology of anadromous coastal cutthroat trout oncorhynchus clarkii clarkii in a tributary of south puget sound, washington. North American Journal of Fisheries Management, 36(2), 375-384. doi: 10.1080/02755947.2015.1129001

Madel, G., \& Losee, J. (2016). Research and monitoring of adult Oncorhynchus mykiss in the nisqually river (Tech. Rep.). Washington Department of Fish and Wildlife.

Needham, P., \& Taft, A. (1934). Observations on the spawning of steelhead trout. Trans. Amer. Fish Soc., 64.

NOAA. (2020). National weather forecast service. https://w2. weather.gov/ climate/xmacis.php?wfo=sew. (Accessed: 2020-03-10)

Phillips, J., Samonil, P., Pawlik, ., Trochta, J., \& Dank, P. (2016, 10). Domination of hillslope denudation by tree uprooting in an old-growth forest. Geomorphology, 276. doi: 10.1016/j.geomorph.2016.10.006

Polvi, L., Dietze, M., Lotsari, E., Turowski, J., \& Lind, L. $\quad$ (in review). $\quad$ Seismic monitoring of a subarctic river: seasonal variations in hydraulics, sediment transport and ice dynamics. in review. Journal of Geophysical Research: Earth 
Surface.

Polvi, L., \& Sarneel, J. (2018). Ecosystem engineers in rivers: An introduction to how and where organisms create positive biogeomorphic feedbacks. WIREs Water, 5(2), e1271. doi: 10.1002/wat2.1271

Quinn, T. (2018). The behavior and ecology of pacific salmon and trout. University of Washington Press.

Rand, P. S., \& Fukushima, M. (2014). Estimating the size of the spawning population and evaluating environmental controls on migration for a critically endangered asian salmonid, sakhalin taimen. Global Ecology and Conservation, 2, 214 - 225. doi: https://doi.org/10.1016/j.gecco.2014.09.007

Rennie, C., \& Millar, R. (2000). Spatial variability of streambed scour and fill: A comparison of scour depth in chum salmon (oncorhynchus keta) redds and adjacent bed. Canadian Journal of Fish and Aquatic Science, 57, 928-938. doi: 10.1016/j.geomorph.2016.10.006

Schmandt, B., Gaeuman, D., Stewart, R., Hansen, S., Tsai, V., \& Smith, J. (2017). Seismic array constraints on reach-scale bedload transport. Geology, 45, 299302. doi: 10.1130/G38639.1

Turowski, J. M., Dietze, M., Schöpa, A., Burtin, A., \& Hovius, N. (2016). Vom flüstern, raunen und grollen der landschaft. seismische methoden in der geomorphologie. System Erde, 6, 56-61. doi: 10.2312/GFZ.syserde.06.01.9

USGS. (2020). National water information system: Web interface. https:// waterdata.usgs.gov/nwis/uv?site_no=12087000. (Accessed: 2020-03-10)

Viles, H. (1988). Biogeomorphology. Blackwell.

Welch, P. (1967). The use of fast Fourier transform for the estimation of power spectra: A method based on time averaging over short, modified periodograms. IEEE Transactions on Audio and Electroacoustics, 15, 70-73. 